\title{
AVALIAÇÃO ERGONÔMICA APLICADO A HABITAÇÃO DE INTERESSE SOCIAL
}

OLIVEIRA, Valéria Costa de (1);

SANTOS, Emílio Gabriel Freire dos (2);

OLIVEIRA, Rafael Alves de (3)

(1) Instituto Federal de Rondônia, Mestre

e-mail:valeria.oliveira@ifro.edu.br

(2) Instituto Federal de Rondônia, Discente de curso técnico em edificações

e-mail:emiliogabriel564@gmail.com

(3) Instituto Federal de Rondônia, Discente de curso técnico em edificações

e-mail: rafa22ro@gmail.com

\begin{abstract}
RESUMO
As habitações de interesse social (HIS) oferecem pouca ou nenhuma possibilidade de adaptação, uma vez que são projetadas de forma atender a redução de custos. Desta forma apresentam a tendência de prejudicar os fatores ergonômicos que influenciam os espaços edificados, seus equipamentos e mobiliário, hábito, técnicas de arranjos e fluxos de circulação. O objetivo do trabalho trata de uma avaliação ergonômica aplicado em cinco projetos arquitetônicos de HIS. A metodologia utilizada foi baseada no índice de avaliação ergonômica do dimensionamento da habitação de Boueri. Os resultados mostraram que as habitações apresentam índices ergonômicos classificados de regulares a precários.
\end{abstract}

Palavras chave: ergonomia; habitação de interesse social; índices.

\begin{abstract}
Social Interest Housing (HIS) offers little or no adaptability since it is designed to meet cost reduction. In this way they present a tendency to undermine the ergonomic factors that influence the built spaces, their equipment and furniture, habit, techniques of arrangements and circulation flows. The objective of this work is an ergonomic evaluation applied to five HIS architectural projects. The methodology used was based on the index of ergonomic evaluation of the housing design of Boueri. The results showed that the dwellings present ergonomic indexes classified as regular to precarious.
\end{abstract}

Keywords: ergonomics; housing of social interest; indexes.

\section{INTRODUÇÃO}

A habitação é um produto complexo em razão de suas atribuições e multiplicidade de funções que desempenha, e sua complexidade é devida à dimensão que assume na vida do ser humano (MARTINS et al, 2007). 


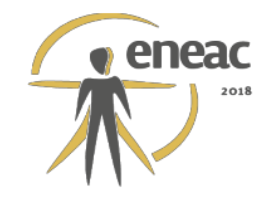

A redução das dimensões da habitação de interesse social (HIS) compromete a qualidade espacial, pois os ambientes são projetados com dimensões desvinculadas das exigências espaciais para a adequada execução das tarefas cotidianas, o que compromete 0 desempenho exigido para edificações pela Norma Técnica NBR 15575-1 (ABNT, 2013), pois os ambientes são projetados com dimensões inadequadas à funcionalidade, ergonomia $\mathrm{e}$ acessibilidade. Vale ressaltar que a qualidade residencial engloba vários aspectos: social, o econômico, o cultural e tecnológico, e as condições do meio que a envolve.

Desta forma Lapetina (2007) resumiu a qualidade residencial na adequação da habitação e sua envolvente às necessidades dos moradores, porém por possuir características próprias, deve incorporar também; possibilidade de adequação em longo prazo; possibilidade de adequação sócio-cultural, permitindo a compatibilização das diversas necessidades de cada morador dentro de uma só casa.

Para Damé (2008) é visível a necessidade da melhoria da qualidade espacial dos projetos, o que torna prioritária a concepção de unidades habitacionais com dimensões voltadas para a funcionalidade e conforto dos usuários.

Em relação à normalização, no ano de 2013 entrou em vigor a norma de desempenho NBR 15575, destinada a edificações habitacionais, com requisitos e critérios de segurança, habitabilidade e sustentabilidade. Quanto a ergonomia podemos citar o trabalho relevante de Boueri (2004) que avalia conforme índices de avaliação ergonômica do dimensionamento da habitação.

\section{2. ÍNDICES DE AVALIAÇÃO ERGONÔMICA DO DIMENSIONAMENTO DA HABITAÇÃO CONFORME BOUERI (2004)}

Os critérios de avaliação de Boueri (2004) considera a delimitação de faixas de áreas de varreduras das habitação e do ambientes classificados em:

- Bom, 4;

- Satisfatório, 3;

- Regular, 2;

- Precário, 1.

A metodologia de Boueri (2004), os índices de avaliação ergonômica do dimensionamento da habitação, envolvem cincos critérios:

- Área útil da habitação - capacidade dimensional da habitação em suportar, no conjunto dos ambientes, a execução das tarefas domésticas de formas adequadas, eficientes e seguras, obtida pela divisão da área útil total da habitação pelo número de usuários expressa em metros quadrados e que classificam a habitação (tabela 1).

Tabela 1 - Área útil da habitação.

\begin{tabular}{|c|c|}
\hline İndice & Critério \\
\hline B-4 & 16 a $14 \mathrm{~m}^{2}$ habitantes \\
\hline S-3 & 14 a $12 \mathrm{~m}^{2}$ habitantes \\
\hline R-2 & 12 a $10 \mathrm{~m}^{2}$ habitantes \\
\hline PR-1 & 10 a $8 \mathrm{~m}^{2}$ habitantes \\
\hline
\end{tabular}

Fonte: Adaptada de Boueri (2004) 


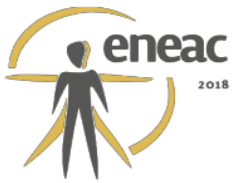

- Área útil do ambiente - capacidade dimensional do ambiente em suportar a execução das tarefas domésticas de forma adequada, eficiente e segura (tabela 2);

Tabela 2 - Área útil do ambiente.

\begin{tabular}{|c|c|c|c|c|c|c|c|}
\hline Índice & Sala & $\begin{array}{c}\text { Dormitório } \\
\text { casal }\end{array}$ & $\begin{array}{c}\text { Dormitóri } \\
\mathbf{0} \\
\text { duplo }\end{array}$ & $\begin{array}{c}\text { Dormitório } \\
\text { simples }\end{array}$ & Cozinha & $\begin{array}{c}\text { Área de } \\
\text { serviço }\end{array}$ & Banheiro \\
\hline $\mathrm{B}-4$ & $\begin{array}{c}18 \mathrm{a} \\
15 \\
\mathrm{~m}^{2}\end{array}$ & $\begin{array}{c}18 \mathrm{a} 15 \\
\mathrm{~m}^{2}\end{array}$ & $\begin{array}{c}15 \mathrm{a} 12 \\
\mathrm{~m}^{2}\end{array}$ & $\begin{array}{c}12 \mathrm{a} 10 \\
\mathrm{~m}^{2}\end{array}$ & $\begin{array}{c}12 \mathrm{a} 10 \\
\mathrm{~m}^{2}\end{array}$ & $\begin{array}{c}12 \mathrm{a} 10 \\
\mathrm{~m}^{2}\end{array}$ & $6 \mathrm{a} 5,5 \mathrm{~m}^{2}$ \\
\hline $\mathrm{S}-3$ & $\begin{array}{c}15 \mathrm{a} \\
12 \\
\mathrm{~m}^{2}\end{array}$ & $\begin{array}{c}15 \mathrm{a} 12 \\
\mathrm{~m}^{2}\end{array}$ & $\begin{array}{c}12 \mathrm{a} 10 \\
\mathrm{~m}^{2}\end{array}$ & $\begin{array}{c}10 \mathrm{a} 9 \\
\mathrm{~m}^{2}\end{array}$ & $\begin{array}{c}10 \mathrm{a} 8 \\
\mathrm{~m}^{2}\end{array}$ & $\begin{array}{c}10 \mathrm{a} 8 \\
\mathrm{~m}^{2}\end{array}$ & $5,5 \mathrm{a} 5 \mathrm{~m}^{2}$ \\
\hline $\mathrm{R}-2$ & $\begin{array}{c}12 \mathrm{a} \\
9 \\
\mathrm{~m}^{2}\end{array}$ & $\begin{array}{c}12 \mathrm{a} 9 \\
\mathrm{~m}^{2}\end{array}$ & $\begin{array}{c}10 \mathrm{a} 8 \\
\mathrm{~m}^{2}\end{array}$ & $9 \mathrm{a} 8 \mathrm{~m}^{2}$ & $8 \mathrm{a} 6 \mathrm{~m}^{2}$ & $8 \mathrm{a} 6 \mathrm{~m}^{2}$ & $5 \mathrm{a} 4,5 \mathrm{~m}^{2}$ \\
\hline PR-1 & $\begin{array}{c}9 \mathrm{a} 6 \\
\mathrm{~m}^{2}\end{array}$ & $9 \mathrm{a} 6 \mathrm{~m}^{2}$ & $8 \mathrm{a} 6 \mathrm{~m}^{2}$ & $8 \mathrm{a} 6 \mathrm{~m}^{2}$ & $6 \mathrm{a} 4 \mathrm{~m}^{2}$ & $6 \mathrm{a} 4 \mathrm{~m}^{2}$ & $4,5 \mathrm{a} 4 \mathrm{~m}^{2}$ \\
\hline
\end{tabular}

Fonte: Adaptada de Boueri (2004)

- Composição do mobiliários e equipamento - capacidade do ambiente em de receber mobiliário e ou equipamento necessários ao desempenho das atividades domésticas, podendo suportar um acréscimo ou uma inovação de atividades dentro deste espaço (tabela 3);

Tabela 3 - Composição de mobiliário e equipamento.

\begin{tabular}{|c|c|}
\hline Índice & Critério \\
\hline B-4 & $\begin{array}{l}\text { O ambiente suporta adicionar mobiliário e equipamento básicos com } \\
\text { dimensões usuais }\end{array}$ \\
\hline S-3 & $\begin{array}{c}\text { O ambiente suporta o mobiliário e equipamento básico com } \\
\text { dimensões usuais }\end{array}$ \\
\hline $\mathrm{R}-2$ & $\begin{array}{l}\text { O ambiente suporta o mobiliário e equipamento básico com } \\
\text { dimensões reduzidas aos usuais }\end{array}$ \\
\hline PR-1 & $\begin{array}{l}\text { O ambiente não suporta o mobiliário e equipamento básico com } \\
\text { dimensões usuais }\end{array}$ \\
\hline
\end{tabular}

Fonte: Adaptada de Boueri (2004)

- Conexões de portas e janelas - É o quanto à locação da porta e janela permite o ambiente suportar flexibilidade no arranjo do mobiliário e equipamento sem prejudicar a circulação, o acesso e a execução das tarefas domésticas de forma adequada, eficiente e segura (tabela 4); 
Tabela 4 - Conexões de portas e janelas.

\begin{tabular}{|c|c|}
\hline Índice & Critério \\
\hline B-4 & A conexão suporta grande flexibilidade no arranjo de mobiliário e equipamento básicos. \\
\hline S-3 & A conexão suporta pouca flexibilidade no arranjo de mobiliário e equipamento básicos \\
\hline R-2 & A conexão não suporta flexibilidade no arranjo de mobiliário e equipamento básicos. \\
\hline PR-1 & A conexão cria conflitos no arranjo e uso do mobiliário e equipamento básicos \\
\hline
\end{tabular}

Fonte: Adaptada de Boueri (2004)

- Tipologia da habitação e ciclo familiar - É o quanto à tipologia da habitação suporta a composição da família durante o ciclo completo da família (tabela $5)$.

Tabela 5 - Tipologia da habitação e ciclo familiar.

\begin{tabular}{|c|c|}
\hline Índice & Critério \\
\hline B-4 & A tipologia da habitação suporta adequadamente todo o ciclo familiar \\
\hline S-3 & A tipologia da habitação suporta adequadamente $2 / 3$ de todo o ciclo familiar \\
\hline R-2 & A tipologia da habitação suporta adequadamente $1 / 2$ de todo o ciclo familiar \\
\hline PR-1 & A tipologia da habitação suporta adequadamente $1 / 3$ de todo o ciclo familiar \\
\hline
\end{tabular}

Fonte: Adaptada de Boueri (2004)

\section{METODOLOGIA}

A pesquisa foi realizada por meio de consultas em trabalhos acadêmicos que tratam de ergonomia e qualidade de projetos de habitações. Desta forma optou-se por utilizar o método do índice ergonômicos da habitação de Boueri (2004) e as dimensões dos móveis utilizou o Anexo G da ABNT NBR 15275-1 (ABNT, 2013).

\subsection{Caracterização das HIS}

A segunda etapa da pesquisa, a fase exploratória, consistiu no levantamento e análise de cinco projetos de HIS. 


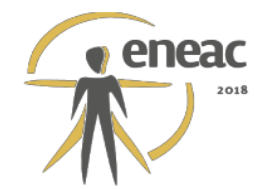

Tabela 6 - Caracterização das HIS - estudos de caso.

\begin{tabular}{|c|c|c|c|}
\hline HIS & Tipologia & Ambientes & Sistema construtivo \\
\hline A & $\begin{array}{c}\text { Unifamiliar } \\
\text { Geminada }\end{array}$ & $\begin{array}{c}\text { Sala, cozinha, banheiro, } \\
\text { quarto casal, ampliação para } \\
\text { um quarto }\end{array}$ & $\begin{array}{c}\text { Alvenaria sem função } \\
\text { estrutural de tijolos e } \\
\text { blocos cerâmicos }\end{array}$ \\
\hline B & Multifamiliar & $\begin{array}{c}\text { Sala estar/jantar, cozinha, } \\
\text { banheiro, quarto casal e } \\
\text { quarto duas pessoas }\end{array}$ & $\begin{array}{c}\text { Alvenaria estrutural de } \\
\text { blocos vazados de } \\
\text { concreto }\end{array}$ \\
\hline C & $\begin{array}{c}\text { Unifamiliar } \\
\text { Geminada }\end{array}$ & $\begin{array}{c}\text { Sala estar/jantar, cozinha, } \\
\text { banheiro, quarto casal e } \\
\text { quarto duas pessoas }\end{array}$ & $\begin{array}{c}\text { Alvenaria sem função } \\
\text { estrutural de tijolos e } \\
\text { blocos cerâmicos }\end{array}$ \\
\hline D & $\begin{array}{c}\text { Unifamiliar } \\
\text { Geminada }\end{array}$ & $\begin{array}{c}\text { Sala estar/jantar, cozinha, } \\
\text { banheiro, quarto casal e } \\
\text { quarto duas pessoas }\end{array}$ & $\begin{array}{c}\text { Alvenaria estrutural de } \\
\text { blocos vazados de } \\
\text { concreto }\end{array}$ \\
\hline E & $\begin{array}{c}\text { Unifamiliar } \\
\text { Geminada }\end{array}$ & $\begin{array}{c}\text { Sala estar/jantar, cozinha, } \\
\text { banheiro, quarto casal e } \\
\text { quarto duas pessoas }\end{array}$ & $\begin{array}{c}\text { Paredes estruturais de } \\
\text { concreto armado }\end{array}$ \\
\hline
\end{tabular}

Fonte: Autores

\subsection{Layouts dos projetos das HIS}

As dimensões dos móveis (tabela 7) foram adequados conforme a ABNT NBR 15575-1, Anexo G, Tabela 2 - Dimensões mínimas de mobiliário e circulação (ABNT, 2013). Após a classificação de cada mobiliário e equipamento, estes foram desenhados nos softwares AutoCAD e Sketchup. A elaboração de layouts, para cada atividade, permite a análise da associação de um conjunto definido de mobiliário e equipamentos, conferindo a possibilidade de dois ou mais arranjos e/ou de mais de uma atividade com os mesmos itens.

As circulações e o mobiliários mínimos também foram avaliados conforme a norma de desempenho, anexo G (tabela 8). 


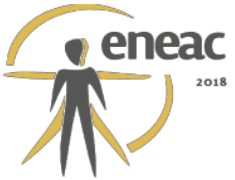

Tabela 7 - Dimensões dos móveis padrões utilizados nos ambientes.

\begin{tabular}{|c|c|c|c|}
\hline \multirow{2}{*}{ Ambientes } & Móvel ou Equipamento & \multicolumn{2}{|c|}{ Dimensões (m) } \\
\cline { 2 - 4 } & & $\mathbf{L}$ & $\mathbf{P}$ \\
\hline \multirow{2}{*}{ Sala de Estar } & Sofá de 2 lugares com braço & 1,20 & 0,70 \\
\cline { 2 - 4 } & Estante/Armário para TV & 0,50 & 0,80 \\
\hline Sala de Estar/Jantar & Mesa Redonda para 4 lugares & D $=0,95$ & \\
\hline \multirow{3}{*}{ Cozinha } & Pia & 1,20 & 0,50 \\
\cline { 2 - 4 } & Fogão & 0,55 & 0,60 \\
\cline { 2 - 4 } & Geladeira & 0,70 & 0,70 \\
\hline \multirow{3}{*}{ Dormitório Casal } & Cama de Casal & 1,40 & 1,90 \\
\cline { 2 - 4 } & Criado Mudo x & 0,50 & 0,50 \\
\hline \multirow{2}{*}{ Dormitório para 2 } & Guarda-Roupa & 1,60 & 0,50 \\
\cline { 2 - 4 } pessoas & Camas de Solteiro & 0,80 & 1,90 \\
\cline { 2 - 4 } & Criado Mudo & 0,50 & 0,50 \\
\hline \multirow{2}{*}{ Banheiro } & Guarda-Roupa & 1,50 & 0,50 \\
\cline { 2 - 4 } & Lavatório & 0,39 & 0,29 \\
\hline \multirow{2}{*}{ Área de Serviço } & Vaso Sanitário & 0,60 & 0,60 \\
\cline { 2 - 4 } & Tanque & 0,52 & 0,53 \\
\hline
\end{tabular}

Fonte: Adaptada da ABNT NBR 15575-1, Anexo G

Tabela 8 - Circulações e acessos mínimos dos ambientes.

\begin{tabular}{|c|l|}
\hline Ambiente & \multicolumn{1}{|c|}{ Requisitos } \\
\hline Sala de Estar & $\begin{array}{l}\text { Espaço de } 0,50 \mathrm{~m} \text { na frente do assento, largura mínima de } 2,40 \mathrm{~m} \text { e } \\
\text { Espaço obrigatório para estante ou armário para TV }\end{array}$ \\
\hline Sala estar/jantar & Circulação mínima de $0,75 \mathrm{~m}$ à partir da borda da mesa \\
\hline Sala de jantar Copa/cozinha & Largura mínima de 2,40 m \\
\hline Cozinha & $\begin{array}{l}\text { Circulação mínima 0,85 } \mathrm{m} \text { frontal à pia, fogão e geladeira e Largura } \\
\text { mínima da cozinha: } 1,50 \mathrm{~m}\end{array}$ \\
\hline Dormitório casal & Circulação mínima entre o mobiliário e/ou paredes de 0,50 m \\
\hline Dormitório para 2 pessoas & $\begin{array}{l}\text { Circulação mínima entre as camas de 0,60 m e Demais circulações: } \\
\text { mínimo de 0,50 m }\end{array}$ \\
\hline Banheiro & Circulação mínima de $0,4 \mathrm{~m}$ frontal ao vaso, lavatório e bidê \\
\hline
\end{tabular}

Fonte: Adaptada da ABNT NBR 15575-1, Anexo G 


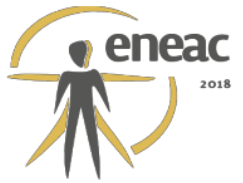

\section{RESULTADOS E DISCUSSÕES}

Para cada HIS foram avaliados os critérios conforme Boueri (2004).

\subsection{Critério - Área útil da habitação}

Os resultados foram regulares quanto ao critério da área útil da habitação com exceção da HIS A que na fase construtiva acolhe apenas um casal e assim a área é satisfatória, tabela 9.

Tabela 9 - Avaliação conforme o critério da área útil da habitação.

\begin{tabular}{|c|c|c|c|c|}
\hline HIS & $\begin{array}{c}\text { Área útil total } \\
\left(\mathbf{m}^{2}\right)\end{array}$ & $\begin{array}{c}\text { Habitante } \\
\text { (unid.) }\end{array}$ & $\begin{array}{c}\text { Área útil/ } \\
\text { habitante }\end{array}$ & Critério \\
\hline A & 27,50 & 2 & 13,75 & Satisfatório - 3 \\
\hline B & 41,39 & 4 & 10,35 & Regular - 2 \\
\hline C & 40,80 & 4 & 10,2 & Regular - 2 \\
\hline D & 36,84 & 4 & 9,21 & Regular - 2 \\
\hline E & 41,74 & 4 & 10,44 & Regular - 2 \\
\hline
\end{tabular}

\subsection{Critério - Área útil do ambiente}

Quanto ao critério de avaliação da área útil por ambiente observou-se que as áreas das cozinhas e dos banheiros foram classificadas como precárias para todas as HIS, os quartos foram considerados de satisfatórios a precários e as salas de satisfatórias a regulares, tabela 10.

Tabela 10 - Avaliação da Área útil do ambiente.

\begin{tabular}{|c|c|c|c|c|c|}
\hline Índice & Sala & $\begin{array}{c}\text { Dormitório } \\
\text { casal }\end{array}$ & $\begin{array}{c}\text { Dormitório } \\
\text { duplo }\end{array}$ & Cozinha & Banheiro \\
\hline B-4 & - & - & - & - & - \\
\hline S-3 & HIS B & HIS A, & HIS A & - & - \\
\hline R-2 & $\begin{array}{c}\text { HIS A, } \\
\text { C, D e E }\end{array}$ & HIS B e E & HIS E & - & - \\
\hline PR-1 & - & HIS C e D & HIS B, C, D & $\begin{array}{c}\text { HIS A, B, } \\
\text { C, D e E }\end{array}$ & $\begin{array}{c}\text { HIS A, B, } \\
\text { C, D e E }\end{array}$ \\
\hline
\end{tabular}

Fonte: Autores

\subsection{Critério - Composição de mobiliário e equipamento}

Todas as HIS foram consideradas nas classificações de regular (R-2) a precárias (PR-1). No caso da HIS A, a partir da análise do layout é possível verificar que apesar da sala de estar 


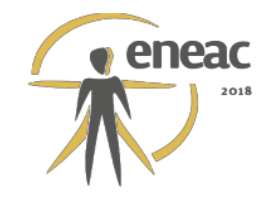

comportar o mobiliário mínimo recomendado pelo anexo G da NBR 15575 não permite uma circulação adequada em virtude da localização da mesa de refeições.

Nos quartos a recomendação da norma de desempenho não é atendida quanto a circulação mínima de $50 \mathrm{~cm}$, bem como mostra a dificuldade de acesso ao guarda-roupa conforme 0 layout.

Figura 1 - Layout HIS A

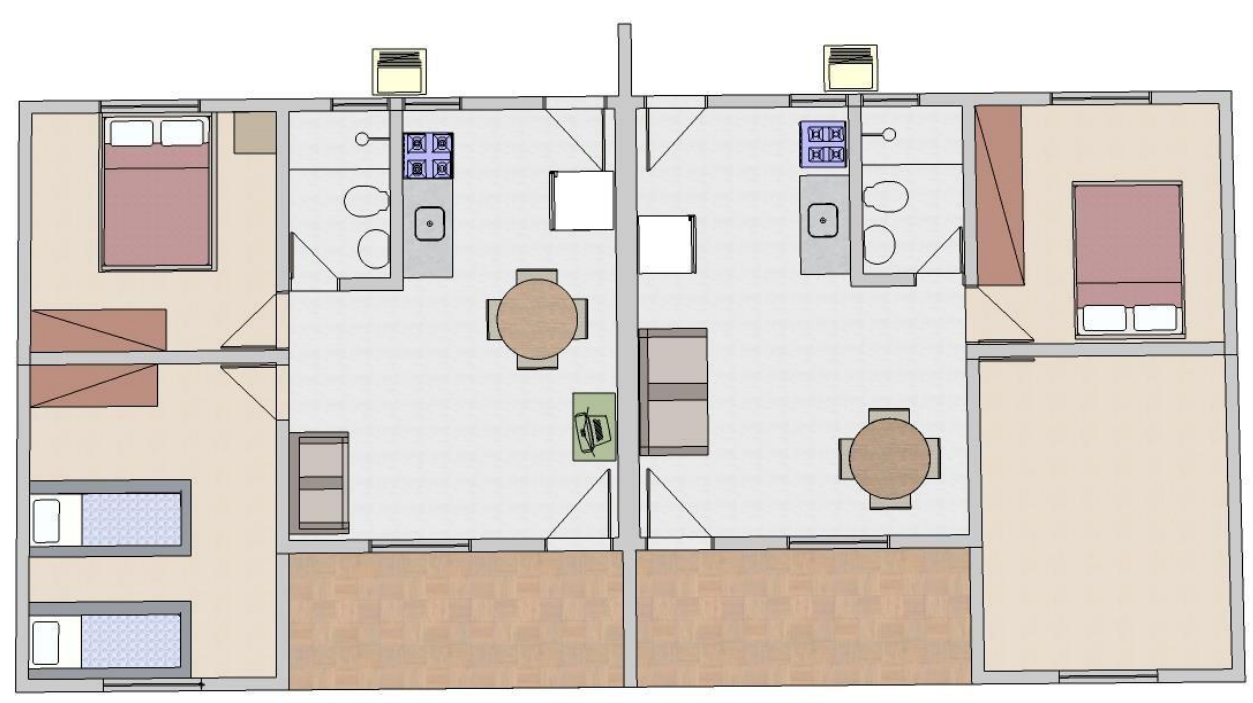

Fonte: Autores

A HIS B (figura 2) trata-se de edifício de 4 pavimentos (térreo e 3 pavimentos tipos), sendo 4 unidades por pavimento tipo. O apartamento atende de forma parcial a NBR 15575-1 devido o quarto previsto para duas pessoas não comportar o mobiliário e a circulação mínima de $0,60 \mathrm{~m}$ entre as camas recomendados e o quarto de casal não atender a circulação mínima 0,50 m entre o mobiliário e/ou paredes de $0,50 \mathrm{~m}$.

Para a mesa de quatro lugares a NBR 15575-1 recomenda circulação mínima de 0,75 m à partir da borda da mesa (espaço para afastar a cadeira e levantar) e dessa forma o projeto padrão não atendeu a indicação.

A ABNT NBR 15575-1 indica para a circulação mínima de $0,85 \mathrm{~m}$ frontal à pia, fogão e geladeira no ambiente da cozinha, que tem largura mínima de $1,50 \mathrm{~m}$. No entanto a HIS $B$ não comporta a largura mínima da geladeira de $70 \mathrm{~cm}$. Outra não conformidade refere-se quanto a área de giro de $360^{\circ}$ exigida para o cadeirante em um círculo de diâmetro de $1,50 \mathrm{~m}$ não é obtida com a inserção do mobiliário. 


\section{(x) $^{\text {reace }}$}

Figura 2 - Layout HIS B.

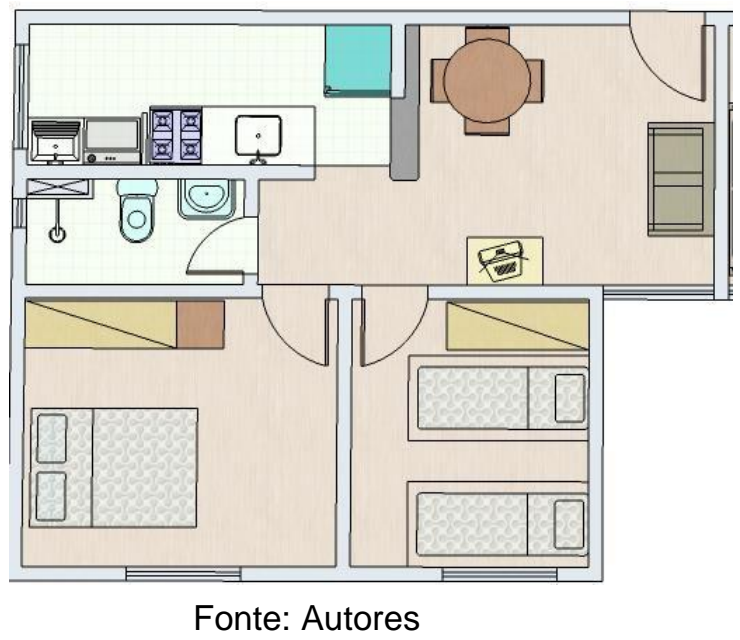

O layout da HIS C (figura 3) atende de forma parcial a ABNT NBR 15575-1 devido o dormitório previsto para duas pessoas não comportar o mobiliário e a circulação mínima de $0,60 \mathrm{~m}$ entre as camas recomendados e o dormitório destinado para o casal não atender a circulação mínima $0,50 \mathrm{~m}$ entre o mobiliário e/ou paredes de $0,50 \mathrm{~m}$. A funcionalidade do quarto do casal foi comprometida devido a redução de sua área em prol do aumento das dimensões do banheiro.

Figura 3 - Layout HIS C.

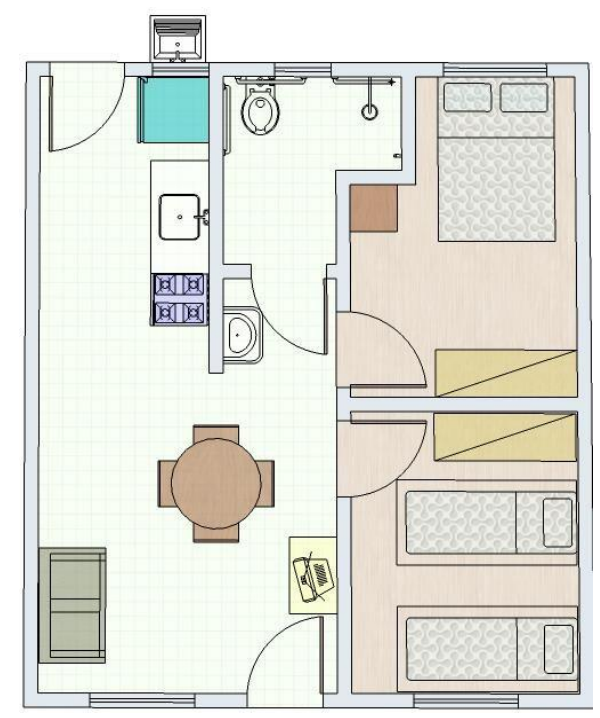

Fonte: Os autores

A HIS D (figura 4) atende de forma parcial a ABNT NBR 15575-1 devido a mesa de quatro lugares não atender a circulação mínima de $0,75 \mathrm{~m}$ à partir da borda da mesa (espaço para afastar a cadeira e levantar). Assim como na edificação $B$, a edificação $D$ não atende a recomendação para a circulação mínima de $0,85 \mathrm{~m}$ frontal à pia, fogão e geladeira no ambiente da cozinha, que tem largura mínima de 1,50 $\mathrm{m}$ e assim, não comportar a largura mínima da geladeira de $70 \mathrm{~cm}$. 


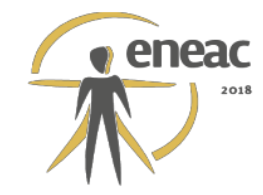

O dormitório previsto para ser duplo não se adequa as dimensões dos móveis, circulações mínimas conforme a norma de desempenho.

Figura 4 - Layout HIS D.

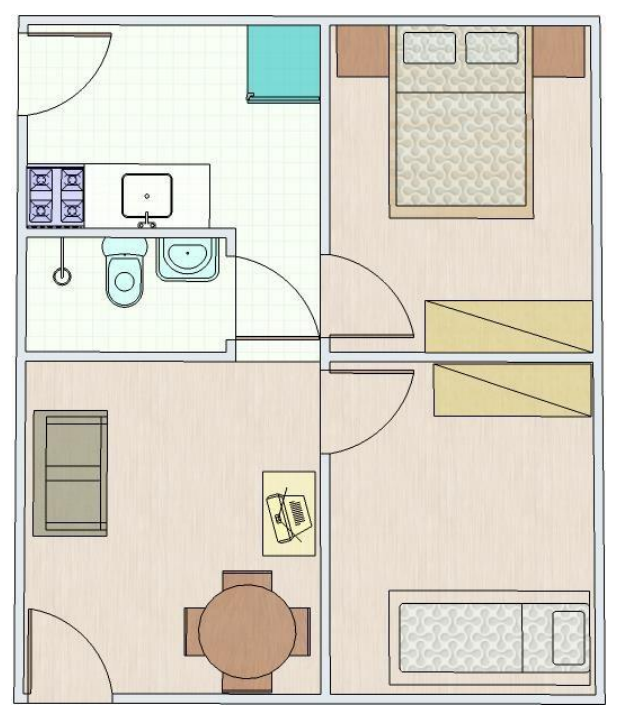

Fonte: Os autores

A HIS E (figura 5) é uma concepção do Programa Minha Casa Minha Vida e tem o sistema construtivo inovador, no qual as paredes são executadas com concreto armado de $10 \mathrm{~cm}$, a fundação em radier e laje executada em concreto armado coberta com telha de amianto. $O$ pé direito da casa é de 2,60 $\mathrm{m}$. Se observa que as dimensões dos ambientes atendem o mobiliário mínimo do Anexo G da NBR 15575-1, porém quando o morador da HIS for um cadeirante o desempenho quanto a funcionalidade e acessibilidade não serão atendidos.

Figura 5 - Layout HIS E.

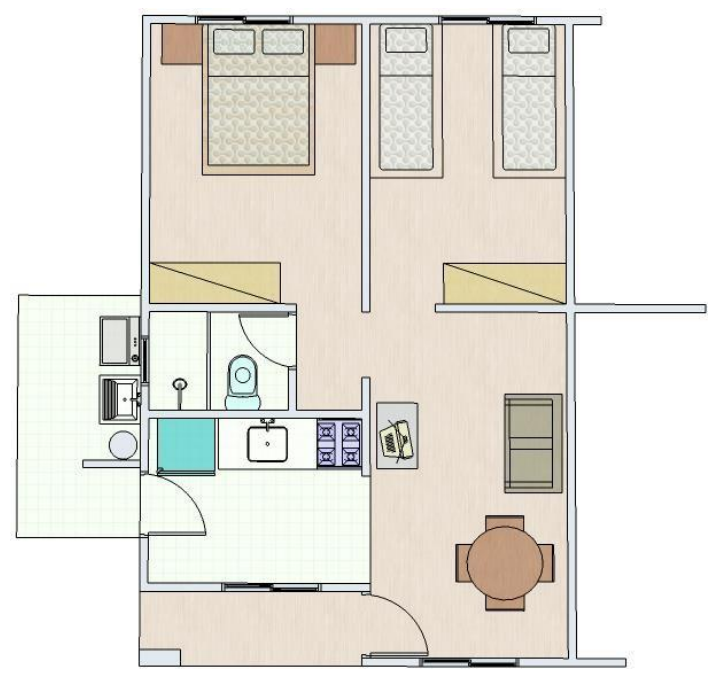

Fonte: Os autores 


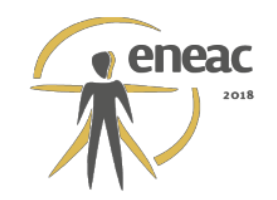

\subsection{Critério - Conexões de Portas e Janelas}

Quanto à locação da porta e janela, permitir que o ambiente suporte a flexibilidade no arranjo do mobiliário e equipamento sem prejudicar a circulação, o acesso e a execução das tarefas domésticas de forma adequada, eficiente e segura; as HIS foram classificadas de regulares a precárias.

A HIS A mostrou que a posição da porta do quarto duplo prejudica a direção frontal do sofá para a televisão na sala, bem como interfere na posição da mesa de jantar. Da mesma forma a HIS D apresentou a mesma problemática.

Quanto ao acesso e execução das tarefas domésticas devido as dimensões reduzidas dos ambientes das HIS mostram-se bastante prejudicadas.

\subsection{Critério - Tipologia da habitação e ciclo familiar}

Não avaliado neste trabalho.

\section{REFERÊNCIAS BIBLIOGRÁFICAS}

ASSOCIAÇÃO BRASILEIRA DE NORMAS TÉCNICAS. NBR 15575-1: Edificações Habitacionais Desempenho. Requisitos Gerais. Rio de Janeiro, 2013.

BOUERI, J.J. Recomendações Índices Ergonômicos de Dimensionamento e Avaliação da Habitação. Faculdade de arquitetura e urbanismo da Universidade de São Paulo. São Paulo. São Paulo. 2004.

DAMÉ, L.M. Habitação PAR, Desempenho Ímpar?Uma Avaliação Funcional de Unidades Multifamiliares em Pelotas/RS. Dissertação de mestrado apresentada ao Programa de PósGraduação em Arquitetura e Urbanismo. Universidade Federal de Santa Catarina.Florianópolis, Santa Catarina, 2008.

MARTINS, D.N.; OLIVO, A.A.; MARTINS, A.R.I. Avaliação da qualidade da solução de arranjos físicos de habitações com áreas mínimas, a partir de variáveis geométricas de projeto. Curso de Graduação em Arquitetura e Urbanismo. Universidade Estadual de Maringá, Maringá, Paraná, Brasil.2007.

LAPETINA, C.M.L. Uma Contribuição para Avaliação da Qualidade no Dimensionamento dos Espaços da Habitação. Dissertação de mestrado. Faculdade de arquitetura e urbanismo da Universidade de São Paulo. São Paulo. São Paulo. 2007 